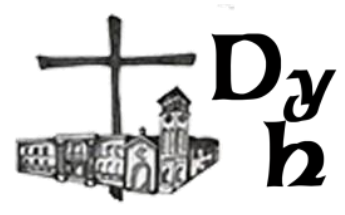

YHWH, el Dios que revela su identidad Jorge de Juan Fernández

Dios y el hombre, vol. 4, n. 1, e057, 2020 ISSN 2618-2858 - https://doi.org/10.24215/26182858e057

https://revistas.unlp.edu.ar/DyH/index Cátedra libre de pensamiento cristiano - UNLP

Seminario Mayor San José

La Plata, Buenos Aires, Argentina

\title{
YHWH, EL DIOS QUE REVELA SU IDENTIDAD
}

\author{
YHWH, the Entity Revealing God \\ Jorge de Juan Fernández \\ jjuaf@unileon.es \\ Universidad de León - León - España
}

\section{Resumen}

Desde hace varias décadas el uso del término Yhwh para referirse a Dios es frecuente encontrarlo en artículos científicos, escritos de divulgación o cantos litúrgicos. Quizá este incremento se haya producido como reacción a la secta de los "Testigos de Jehová". Por este motivo, el presente trabajo quiere explicar de forma sencilla el origen y la exégesis actual de dicho nombre con el que Dios mismo se revela al hombre.

Palabras clave: Yhwh, Dios, revelación, identidad, exégesis

\begin{abstract}
For several decades it is usual to find the term "Yhwh" in scientific articles, disclosure writtings or liturgical songs. It is posible that this increase happened as a reaction of the so called "Jehova witnesses sect". For this reason, the present essay wants to explain in a simple way the origin and current exegesis of this name, that God uses to reveal itself to humanity.
\end{abstract}

Keywords: Yhwh, God, revelation, entity, exegesis. 
El Dios de los patriarcas se revela en un acto de salvación al liberar al pueblo hebreo de la esclavitud de los egipcios. Lo hace con una fórmula: "yo soy el que soy" (Ex 3,14).

A lo largo de la historia han sido muchas las interpretaciones que se han realizado de esta auto-revelación divina. La patrística y la gran escolástica hallan en Ex 3,14 el germen de inspiración y reflexión más intenso para aproximarse al Dios oculto y revelado. La traducción que había realizado la Biblia griega de los

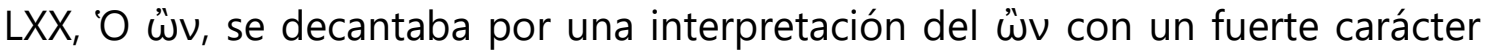
filosófico y ontológico: «El que es», la Esencia misma. Según Gilson (1963), toda la filosofía cristiana encuentra su asiento en el nombre y la definición de Dios como Ser, hallada en Ex 3,14. Posteriormente, Maimónides, exégeta judío, realizó una interpretación similar a la ya señalada. De igual forma ocurre con los reformadores, Lutero, Calvino y Zwinglio, quienes prosiguen en la tradición medieval, introduciendo algunos cambios alegóricos en exégesis y cristológicos en teología.

La exégesis moderna ha querido dejar a un lado las interpretaciones anteriores, acusadas de aplicar una filosofía al texto con un fuerte carácter ontológico y de interpretar el texto hebreo con una mentalidad propiamente helenística. Es evidente que Ex 3,14 no tiene como fin ofrecer una "definición" de la esencia de Dios desde la filosofía, como puede desprenderse de la exégesis realizada por von Rad (1975) o Schild, aunque este último realiza una interpretación existencial (1954). Sin embargo, para Trebolle "el desarrollo filosófico y teológico sobre Ex 3,14 es plenamente legítimo y está ya apuntado en la misma Biblia, en su progresiva enunciación de un monoteísmo estricto" (1985, p. 369).

La teología bíblica actual interpreta este texto desde el enfoque de la historia y la iniciativa salvadora de Yhwh.

A la pregunta de Moisés: “¿cuál es tu nombre?", Dios respondió: "Yo soy el que soy". Y añadió: "Así dirás a los israelitas: 'Yo soy' me ha enviado a vosotros". Siguió Dios diciendo a Moisés: "Así dirás a los israelitas: 'Yhwh (Él es), el Dios de vuestros padres, el Dios de Abraham, el Dios de Isaac y el Dios de Jacob, me ha enviado a vosotros'. Este es mi nombre para siempre, por él seré invocado de generación en generación" (Ex 3, 13-15). 
La pregunta que Moisés realiza para conocer el nombre de Dios supone una pregunta por la naturaleza, la esencia del mismo Dios. En efecto, el pronombre interrogativo que abre esta cuestión en el texto hebreo es nDD. Este se utiliza para interrogar acerca de cosas, por lo que la traducción literal sería "¿Qué cosa es tu nombre?". El autor ha preferido emplear dicho pronombre en lugar de מִי, "quién", más apropiado para interrogar acerca de alguien. Esta nota filológica induce a sostener que "la pregunta de Moisés apunta a la naturaleza de Dios y la respuesta de Dios se ajustará también a esa condición" (Marcone, 2017 , p. 104). Junto a ello ha de señalarse que en el lenguaje semítico el nombre es algo esencial a los seres, mediante el cual se expresa la honda realidad de quien lo lleva, manifestando al mismo tiempo su misión en el mundo.

Dios responde de tres formas diferentes que, aunque tengan el mismo

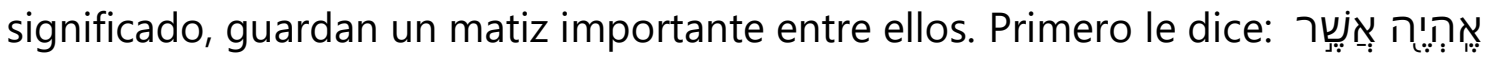
אוּ: "Yo soy el que soy" (Ex 3,14a). Luego le dice: "Yo soy". Y finalmente le dice: persona, la última está conjugada en tercera. Con ello se expresa que las dos primeras son fórmulas que Dios pronuncia sobre sí mismo y que sólo él pronuncia. Por su parte, "Yhwh" "Él es", se trata de la fórmula que el pueblo de Israel debe pronunciar. Resulta igual de significativo que Dios haya repetido por tres veces cómo se le ha de nombrar. Con ello se expresa que él es la plenitud del ser $^{1}$.

Algunos autores consideran que la respuesta ofrecida por Dios ante la pregunta formulada por el pueblo en labios de Moisés es una evasión del Deus absconditus para no revelar su nombre 2 . Como si dijera: " "yo no tengo nombre, no soy un dios como el de los otros pueblos -que no existen-, que se pueden encerrar bajo un concepto y dominar con la invocación de un apelativo. Yo soy el Dios trascendente. El que simplemente es, y no podría no ser»" (Giménez,

\footnotetext{
${ }^{1}$ En la Biblia el número tres representa "totalidad", quizá porque las dimensiones temporales son tres: pasado, presente y futuro. Decir tres equivale a decir "la totalidad" o "siempre". Así, los tres hijos de Noé representan la totalidad de sus descendientes $(G n 6,10)$. El profeta Isaías alude a Dios como el tres veces santo para aludir a la plenitud de la santidad (Is 6,3). Las tres negaciones de Pedro simbolizan todas las veces que Pedro fue infiel a su Maestro (Mt 26,34). Las tres tentaciones que Jesús sufrió del diablo representan todas las tentaciones que tuvo que afrontar durante su existencia terrenal (Mt 4,1-11).

${ }^{2}$ En el trabajo de Lindblom (1964) puede verse una lista amplia de algunos de estos autores.
} 
2011, p. 226). Sin embargo, esta propuesta no ha gozado de mucha acogida, ya que la fórmula "Yo soy" invita a contemplar en este acontecimiento elementos propios de una teofanía.

La revelación de Dios no es ciertamente la primera manifestación de Dios a los hombres, pero sí es la primera auto-manifestación ${ }^{3}$. Con esta deja patente la convicción de que el modo de ser de Dios se revela eminentemente en el trato con Israel, por medio de la historia o de la experiencia personal. A su vez, el pueblo encuentra a Dios en el marco general del día a día, en el mundo en que vive, pues Yhwh no es un Dios que se repliegue en un mundo esotérico.

Frente a un Dios poderoso e inaccesible, Yhwh se revela como un Dios cercano, al que le podemos llamar por su nombre. "Yo soy el que soy" no se presenta como una definición metafísica de Dios, sino como una revelación en la que Dios pone de manifiesto que es amigo, novio amante, esposo fiel... eso significa ser salvador: permanecer junto a su pueblo (de Vaux, 1974).

Dios ha confiado su identidad a los que creen en él; se ha revelado ante ellos en su misterio personal. El don del nombre pertenece al orden de la confidencia y la intimidad.

Decir "Yhwh" significa aceptar la trascendencia de Dios. De aquí que los judíos lo llamaran el "gran nombre", el "único nombre", el "nombre glorioso y terrible", el "nombre oculto y misterioso", el "nombre de la sustancia", el "nombre propio", y más frecuentemente השם המפורש, es decir, "el nombre separado".

Decir "Yhwh" implica la certeza acerca de la presencia de Dios a favor de su pueblo. Ferrada (2008) sostiene que en la afirmación, lo absoluto sería la existencia divina a favor de Israel; lo relativo cómo Israel puede vivenciarla. Por su parte, la historia se presenta como el escenario donde el pueblo debe comprobar y experimentar esta presencia que lo agracia. Lo logrará sólo en la medida en que descubra qué genero de protección y corrección ha ejercido Yhwh con ellos.

\footnotetext{
${ }^{3}$ En este sentido, Kasper (1989, p. 196) recupera el significado revelador en la acepción de autocomunicación divina: "Revelación, en la concepción cristiana, es la autorrevelación de Dios en el sentido de la autocomunicación personal de Dios a los hombres".
} 


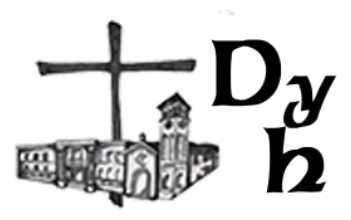

Ex 3,14 debe, por lo tanto, traducirse e interpretarse de acuerdo a la teología y contexto literario en que se inscribe. Al decir "Yo soy el que soy" Dios está revelando su propia identidad, es decir, el que acompaña, el que no abandona. Dios manifiesta que siempre está atento a su pueblo, que no abandona la tarea, que guía a quienes llama y que será un baluarte para Moisés. Esta descripción de Dios es acorde a todo el contexto y se compatibiliza con los versículos que le preceden (v. 12) y le suceden (v. 15), donde se halla también una referencia a Dios.

\section{Referencias}

de Vaux, R. (1974). Historia antigua de Israel I. Madrid: Cristiandad.

Ferrada, A. (2008). Verdad absoluta desde el libro del Éxodo: el nombre divino. Teología y Vida, XLIX, 143-156.

Gilson, E. (1963). The Spirit of Medieval Philosophy. London: Sheed and Ward.

Giménez González, A. (2011). 'Yo soy el que soy' (Ex 3,14): trascendencia e historicidad de Dios en la fe de Israel. En Richi-Alberti, G. (ed.). Dios en la sociedad postsecular (Collectanea Matritensia 8). Madrid: San Dámaso, 219-233.

Kasper, W. (1989). Teología e Iglesia. Barcelona: Herder.

Lindblom, J. (1964). Noch einmal die Deutung des Yahwe-Namens. Annual of the Swedish Theol. Inst., 3, 4-15.

Marcone, J. A. (2017). La revelación del nombre de Yahveh (Ex 3, 13-15). Diálogo, 71, 103-121.

Schild, E. (1954). On Exodus III.14 - 'I am that I am. Vetus Testamentum, 4, 296302.

Trebolle Barrera, J. (1985). La exégesis actual de Éxodo 3,14. En Aranda A. (ed.) et al. Dios y el hombre. VI Simposio Internacional de Teología de la Universidad de Navarra. Pamplona: EUNSA.

von Rad, G. (1975). Teología del Antiguo Testamento I. Salamanca: Sígueme. 